\title{
Association Between Obesity Grade and the Age of the First Acute Coronary Syndrome: Cross-sectional Observational Study
}

Deniz Demirci ( $\nabla$ dddemirci@gmail.com )

Antalya Eğitim ve Araştırma Hastanesi

Duygu E. Demirci

Antalya Eğitim ve Araştırma Hastanesi

\section{Research Article}

Keywords: acute coronary syndrome, age, coronary artery disease, obesity, risk factor

Posted Date: February 24th, 2021

DOl: https://doi.org/10.21203/rs.3.rs-234947/v1

License: (c) (1) This work is licensed under a Creative Commons Attribution 4.0 International License.

Read Full License

Version of Record: A version of this preprint was published at International Journal of Cardiology on December 1st, 2021. See the published version at https://doi.org/10.1016/j.ijcard.2021.11.080. 
1 Association between obesity grade and the age of the first acute coronary syndrome: cross-sectional observational study

$4 \quad$ Deniz Demirci ${ }^{1}$, Duygu E. Demirci ${ }^{1}$

$5 \quad{ }^{1}$ Antalya Training and Research Hospital, Department of Cardiology, Turkey

6 Corresponding author:

7 Deniz Demirci, MD

8 Department of Cardiology, Antalya Training and Research Hospital,

9 Varlık Mh. Kazim Karabekir cad., Department of Cardiology,

10 Antalya - 07100, Turkey

11 Telephone number: +90 5056749302

12 E-mail address: dddemirci@gmail.com

\section{Abstract}

Background: The study evaluates how obesity grade is associated with age during the first acute coronary syndrome (ACS) and examines the effect of cardiovascular (CV) risk factors and the age of first ACS in patients with severe obesity. The effect of the degree of obesity on the age of first ACS may disappear in the absence of other CV risk factors

Methods: We enrolled consecutive patients diagnosed with first episode of ACS between 2014 and 2019, and categorized them by body mass indices (BMI). Independent variables affecting the age of first ACS were examined by linear regression analysis.

Results: A total of 1005 patients (mean age, $57.5 \pm 12.3$ years; $19.3 \%$ female) were included. Patients with ACS with severe obesity were younger than those with ACS in the grade-I obesity, overweight, and normal-weight groups (52.8 \pm 9.9 vs. $55.3 \pm 10.9,56.8 \pm 11.4$, and 
$2461.4 \pm 4.2$, respectively, $p<0.001)$. BMI had a strong, inverse linear relationship with earlier age of first ACS. After adjustment CV risk factors, patients with severe obesity may experience first ACS sooner than those with normal-weight, overweight, and grade-I obesity

$27(-3.4,-5.6$, and -7.1 years, respectively; $p<0.001)$. However, males and females with severe 28 obesity without CV risk factors experienced first ACS episode 22 and 27 years later, 29 respectively.

Conclusion: Patients with severe obesity experience first ACS episode 7.1 years earlier than

31 those with normal-weight. Absence of CV risk factors in people with obesity can improve the 32 potential negative effect of obesity on the ACS age.

33 Trial registration: NCT04578964, 08 October 2020

34 Keywords: acute coronary syndrome; age; coronary artery disease; obesity; risk factor 
Obesity is a highly preventable cause of death and an independent risk factor for cardiovascular diseases (CVD) [1]. Although cardiovascular (CV) events have decreased in the last 2 decades, premature atherosclerotic events have increased in younger individuals [2]. This phenomenon is mainly caused by the increasing prevalence of $\mathrm{CV}$ risk factors, such as obesity, hypertension, and diabetes mellitus (DM). Furthermore, the increasing rate of tobacco use as well as secondhand smoke exposure in young adolescents in low- and middleincome countries increases the incidence of premature CVD [3].

Obesity is characterized by an excess body fat associated with comorbid conditions and increased mortality risk. A body mass index $(\mathrm{BMI}) \geq 25 \mathrm{~kg} / \mathrm{m}^{2}$ defines overweight, BMI $\geq 30 \mathrm{~kg} / \mathrm{m}^{2}$ defines obesity, and BMI $\geq 40 \mathrm{~kg} / \mathrm{m}^{2}$, or BMI $\geq 35 \mathrm{~kg} / \mathrm{m}^{2}$ with comorbidities, defines severe obesity [4]. According the World Health Organization data, worldwide obesity has nearly tripled since 1975 [5]. Overweight and obesity have reached epidemic levels globally [6]. Compared with normal weight, severe obesity is associated with an elevated ratio of total mortality and a marked decline in survival rates [7]. However, the metabolic risk status of individuals with obesity demonstrates heterogeneity. Individuals with obesity that seems to have no obesity-related metabolic complications are classified as metabolically healthy obese (MHO), whereas those who have one of the four criteria of metabolic syndrome (waist circumference excluded) are metabolically unhealthy obese (MUO). Meanwhile, those individuals with metabolic obesity but have normal weights (MONW) are characterized by insulin resistance and hyperinsulinism despite being not obese. CV events are fewer in MHO people than in MONW and MUO patients [8]. The relationship between obesity and coronary artery disease is well documented [9], but studies on the relationship between obesity grade and age during the first acute coronary 
syndrome (ACS) episode are few. Obesity is associated with premature presentation of acute myocardial infarction (MI) [10], and obesity grade inversely correlates with age of patients at first NSTEMI episode [11]. Hence, obesity reduces the age of first ACS. However, obesity was considered as a single-disease group in these studies. The MUO and MHO groups were not examined separately, or the possible effect of the accompanying CV risk factors on the age of ACS was not clearly examined. In the current study, we aimed to determine the relationship between obesity grade and the age of first ACS and to examine the effect of CV risk factors on the age of first ACS in people with severe obesity.

\section{Methods}

This cross-sectional observational study enrolled consecutive adult patients $(>18$ years) who were diagnosed with ACS for the first time and admitted to the intensive coronary care unit of the Antalya Training and Research Hospital between 2014 and 2019. During the hospitalization period, face-to-face interviews and physical examinations were performed, and laboratory findings and CV risk factors were determined. The exclusion criteria were as follows: CVD; chronic renal disease; chronic obstructive pulmonary disease; malignancy; regular use of statins, antiplatelets, or anticoagulants; situations where oral communication with the patient is impossible; situations where coronary angiography could not be performed. Patients with findings that might be related to previous MI on electrocardiography or echocardiography and total occlusion other than "culprit" lesion and no critical stenosis on coronary angiography were also excluded (Supplementary Figure 1). Our study conformed to the principles of the Declaration of Helsinki and was approved by the ethics committee of Antalya Training and Research Hospital, University of Health Sciences (2014-097) (Clinical trial number: NCT04578964). Written informed consent was obtained from all participants. 
Patients admitted to the ICCU with the history of first ACS (n: 1293)

$\downarrow$
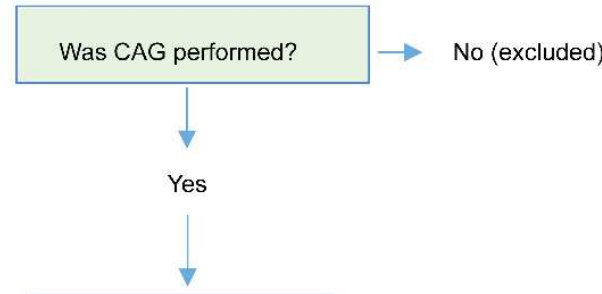

Result of CAG

$\downarrow$

Angiographically confirmed patients

$(n=1127)$

Complete occlusion (n: 614) Incomplete occlusion (n: 513)

(n: 315) One vessel disease ( $\mathrm{n}: 305)$

(n: 177) Two vessel disease ( $\mathrm{n}:$ 148)

(n: 73) Three vessel disease (n: 61)

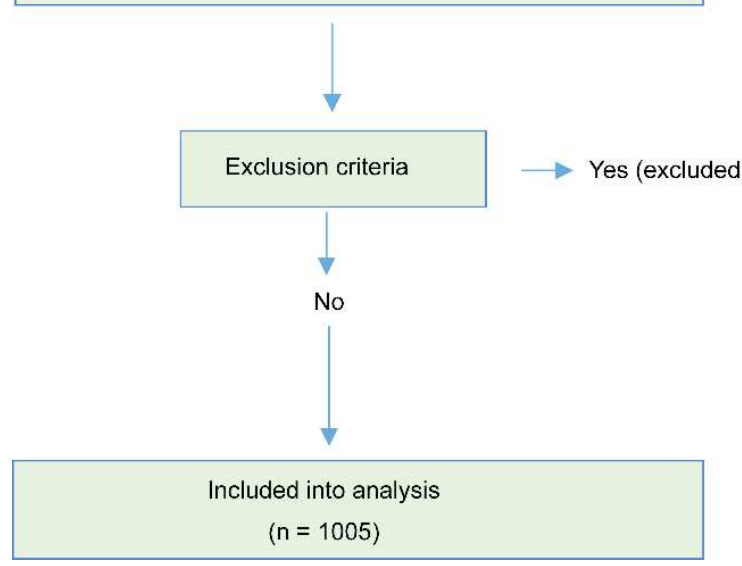

ACS diagnosis is uncertain $(n=32)$

$>\quad$ There is no critical lesion.ACS diagnosis is uncertain (excluded) $(n=110)$

$>$ There is another total occlusion other than culprit lesion. The diagnosis is possibly recurrent ACS (excluded) $(n=24)$ 
Supplementary Figure 1: Patient flowchart of the inclusion/exclusion procedure

96

97

98

99

100

101

102

103

104

105

106

107

108

109

ACS: acute coronary syndrome, CAG: coronary angiography, ICCU: intensive coronary care unit.

The diagnosis of ACS included ST-elevated MI (STEMI), non-ST-elevated MI (NSTEMI), and unstable angina pectoris (USAP). MI was defined according to the fourth universal MI definitions of the 2018 European Society of Cardiology [12]. Our study included type 1 (spontaneous) MI. Acute MI was classified as either STEMI or NSTEMI according to the presence or absence of $\geq 1 \mathrm{~mm}$ of ST-segment elevation in two or more contiguous leads on initial electrocardiography. USAP referred to admitted patients with typical chest pain lasting more than 20 min without increased cardiac markers and STsegment elevation.

The medical history was obtained on the second day of hospitalization. Fasting $(>10$ h) venous blood samples were taken in the first $24 \mathrm{~h}$ of MI to measure blood cholesterol levels. Low-density lipoprotein cholesterol (LDL-C) values were calculated using the 
Friedewald method [13]. For triglyceride levels $>400 \mathrm{mg} / \mathrm{dl}$, "direct LDL-C" measurements were used.

Blood pressure was measured before any treatment that can affect blood pressure levels. In this study, a resting systolic blood pressure $>140 \mathrm{~mm} \mathrm{Hg}$ and/or diastolic blood pressure $>90 \mathrm{~mm} \mathrm{Hg}$ or treatment with antihypertensive medications defined hypertension (HTN). DM was defined as having an established diagnosis of DM or using insulin or oral hypoglycemic drugs. Furthermore, hyperlipidemia (HLD) was defined as having an established diagnosis or treatment with a lipid-lowering agent. A smoker for $>1$ year consuming at least 1 pack per year was considered as a "current smoker."

Psychosocial stress was determined according to patient declaration. Patients were asked the following questions: "When you think about your situation before this heart attack, do you describe yourself as a stressed person?" If the answer was "yes," they were also asked if they had a stress risk factor, and if no, it was considered absent. The following questions were asked to people who were not familiar with the concept of stress: "Do you think you have psychosocial stress about economic status, working conditions, family life, or for any other reason?" Those patients who responded positively were considered to have experienced psychosocial stress.

Moreover, anthropometric parameters were measured within $48 \mathrm{~h}$ of admission. Two trained research nurses measured the weight and height $48 \mathrm{~h}$ after admission. Body weight was measured twice, with the patient in light indoor clothing and without shoes; the average value was then recorded. BMI $\left(\mathrm{kg} / \mathrm{m}^{2}\right)$ was calculated by dividing the body weight by the square of height. BMI was categorized into the following groups: Group 0 (normal weight) for $<25 \mathrm{~kg} / \mathrm{m}^{2}$; Group 1 (overweight) for $25.1-30.0 \mathrm{~kg} / \mathrm{m}^{2}$; Group 2 (obesity) for $30.1-35.0$ $\mathrm{kg} / \mathrm{m}^{2}$; Group 3 (severe obesity) for $>35 \mathrm{~kg} / \mathrm{m}^{2}$ [4]. BMI of $\geq 40 \mathrm{~kg} / \mathrm{m}^{2}$ or $\geq 35 \mathrm{~kg} / \mathrm{m}^{2}$ with 
comorbidities (CAD, DM, HTN, and HLD) defined severe obesity. In this study, all patients had comorbidities such as CAD; therefore, patients with a BMI of $\geq 35 \mathrm{~kg} / \mathrm{m}^{2}$ belonged to the severe-obesity group.

\section{Statistical Analysis}

We present normally distributed continuous variables by arithmetic mean \pm standard deviation, non-normal distributed or ordered variables by median (interquartile range), and categorical variables by frequency and percentage. Normal distribution was analyzed by the Lilliefors-corrected Kolmogorov-Smirnov test. The homogeneity of the variances was determined by Levene's test. The dependent groups of categorical variables were compared by McNemar's test. Normally distributed continuous variables with three or more independent groups were evaluated by one-way analysis of variance, while the non-normally distributed variables were examined by the Kruskal-Wallis test. When the $p$ values from the Kruskal-Wallis test statistics were statistically significant, the group that differed from the other groups was determined by Dunn's post-hoc test. Furthermore, the $p$ values were corrected for multiple comparisons, and the dependent groups were compared using the Wilcoxon test. The age during the first ACS episode was estimated by multiple linear regression analysis. Multiple linear regression analysis was performed with variables determined as $p<0.25$ as a result of univariate statistical analysis. Starting from the most significant value, individual values were added to the model, and the final regression model was established. The LDL-C value was categorized into five groups $(70,100,130,160$, and $190 \mathrm{mg} / \mathrm{dl})$ in the estimated age table for patients with severe obesity; in all other analyses, the LDL-C value was used as a continuous variable. All statistical data were analyzed by $\mathrm{R}$ version 3.4.4, and $p<0.05$ was considered to be statistically significant.

\section{Results}



mean age was $57.4 \pm 12.3$ years, while the mean BMI was $27.9 \pm 4.6 \mathrm{~kg} / \mathrm{m}^{2}$. Based on the

161 had obesity, and $72(7.2 \%)$ had severe obesity. Table 1 lists the demographic characteristics

162 of patients according to the BMI categories.

Table 1: Baseline characteristics of the study population

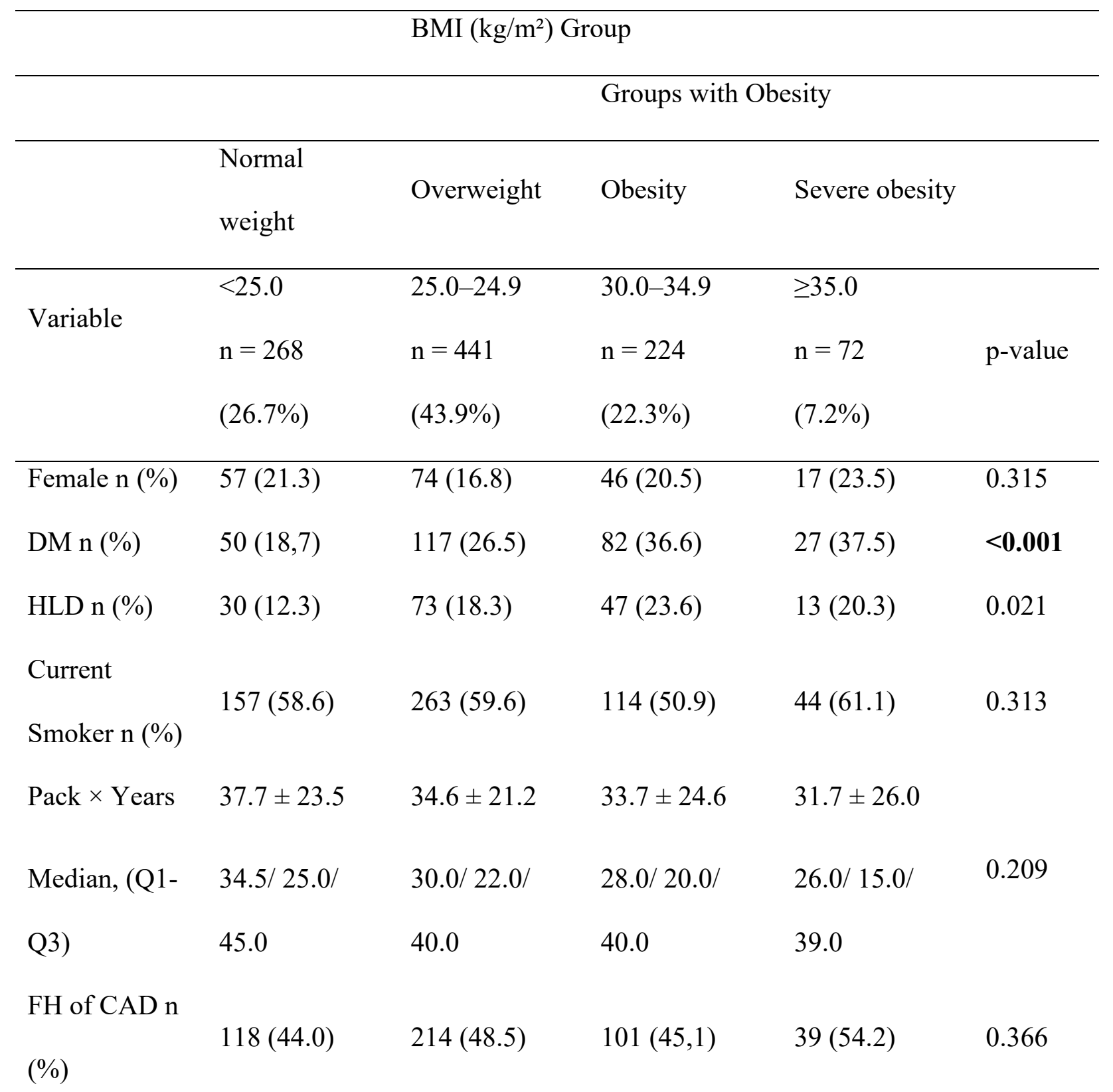




\begin{tabular}{|c|c|c|c|c|c|}
\hline $\begin{array}{l}\text { Psychosocial } \\
\text { stress n (\%) }\end{array}$ & $172(64.2)$ & $324(72.5)$ & $158(70.5)$ & $55(76.2)$ & 0.042 \\
\hline HTN n $(\%)$ & $86(32.1)$ & $176(39.9)$ & $110(49.1)$ & $39(54.1)$ & $<0.001$ \\
\hline Antihypertensi & & & & & \\
\hline ve drug & & & & & \\
\hline Diuretic & $31(11.6)$ & $58(13.2)$ & $29(12.9)$ & $12(16.7)$ & 0.717 \\
\hline $\mathrm{CCB}$ & $24(9.0)$ & $47(10.7)$ & $24(10.7)$ & $10(13.9)$ & 0.663 \\
\hline ARB & $26(9.7)$ & $43(9.8)$ & $26(11.6)$ & $10(13.2)$ & 0.655 \\
\hline ACE-I & $14(5.2)$ & $42(9.5)$ & $17(7.6)$ & $8(11.1)$ & 0.161 \\
\hline BB & $16(6.0)$ & $35(7.9)$ & $18(8.0)$ & $8(11.1)$ & 0.497 \\
\hline Doxazosin & $1(0.4)$ & $4(0.9)$ & $2(0.9)$ & $2(2.8)$ & 0.296 \\
\hline Triglyceride & & & & & \\
\hline$(\mathrm{mg} / \mathrm{dl})$ & & & & & \\
\hline (Median, Q1- & $106.0 / 73.0 /$ & $129.5 / 84.0 /$ & $140.0 / 96.5 /$ & 134.0/92.7/ & $<0.001$ \\
\hline Q3) & 150.0 & 198.0 & 219.0 & 227.0 & \\
\hline LDL-C & & & & & \\
\hline$(\mathrm{mg} / \mathrm{dl})$ & $131.8 \pm 36.6$ & $129.5 \pm 36.6$ & $136.9 \pm 41.1$ & $129.9 \pm 41.9$ & \\
\hline (Median, Q1- & $129.0 / 108.0 /$ & $131.0 / 110.5 /$ & $132.0 / 111.0 /$ & $123.5 / 108.0 /$ & 0.207 \\
\hline Q3) & 155.0 & 159.5 & 164.8 & 148.5 & \\
\hline HDL-C & & & & & \\
\hline$(\mathrm{mg} / \mathrm{dl})$ & $44.2 \pm 11.1$ & $42.3 \pm 9.5$ & $41.7 \pm 9.3$ & $40.3 \pm 7.8$ & \\
\hline (Median, Q1- & $42.0 / 37.0 /$ & $42.0 / 36.0 /$ & $41.0 / 35.8 /$ & $41.0 / 35.0 /$ & 0.047 \\
\hline Q3) & 42.0 & 49.0 & 47.0 & 43.8 & \\
\hline
\end{tabular}


Non-HDL-C

$(\mathrm{mg} / \mathrm{dl})$

$154.2 \pm 41.2 \quad 166.7 \pm 47.9 \quad 168.7 \pm 45.9 \quad 168.5 \pm 57.5$

(Median, Q1-

$150.5 / 125.8 / \quad 160.0 / 135.3 / \quad 164.0 / 136.0 / \quad 157.8 / 135.0 / \quad \mathbf{0 . 0 0 1}$

$\begin{array}{llll}178.0 & 189.0 & 197.0 & 197.0\end{array}$

Q3)

Age All

patients

(years)

NSTEMI /

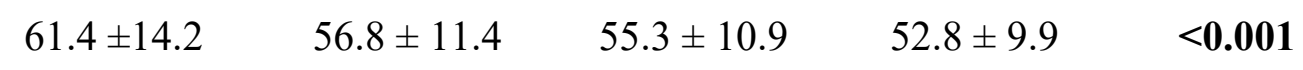

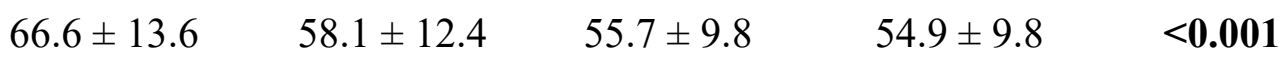

USAP (years)

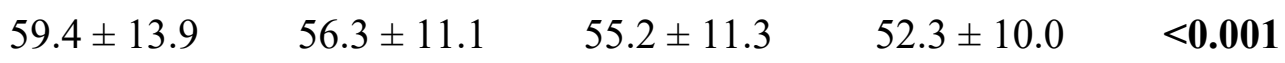

STEMI (years)

ACE-I: angiotensin converting enzyme-inhibitors, ACS: acute coronary syndrome, ARB:

angiotensin receptor blockers, BB: beta blockers, BMI: body mass index, C: cholesterol,

CAD: coronary artery disease, $\mathrm{CCB}$ : calcium channel blockers, DM: diabetes mellitus, FH:

167 family history, HDL: high-density lipoprotein, HLD: hyperlipidemia, HTN: hypertension,

168 LDL: low-density lipoprotein, NSTEMI: non-ST-elevated myocardial infarction, STEMI:

169 ST-elevated myocardial infarction, USAP: unstable angina pectoris

BMI had a strong, inverse linear relationship with age during the first ACS. The mean age at first ACS was $61.4 \pm 14.2$ and $52.8 \pm 9.9$ years for patients with normal weight $(\mathrm{BMI}<$ $\left.25 \mathrm{~kg} / \mathrm{m}^{2}\right)$ and severe obesity $\left(\mathrm{BMI} \geq 35 \mathrm{~kg} / \mathrm{m}^{2}\right)(p<0.0001)$. Figure 1 shows the mean age at first ACS according to BMI categories for both sexes. 


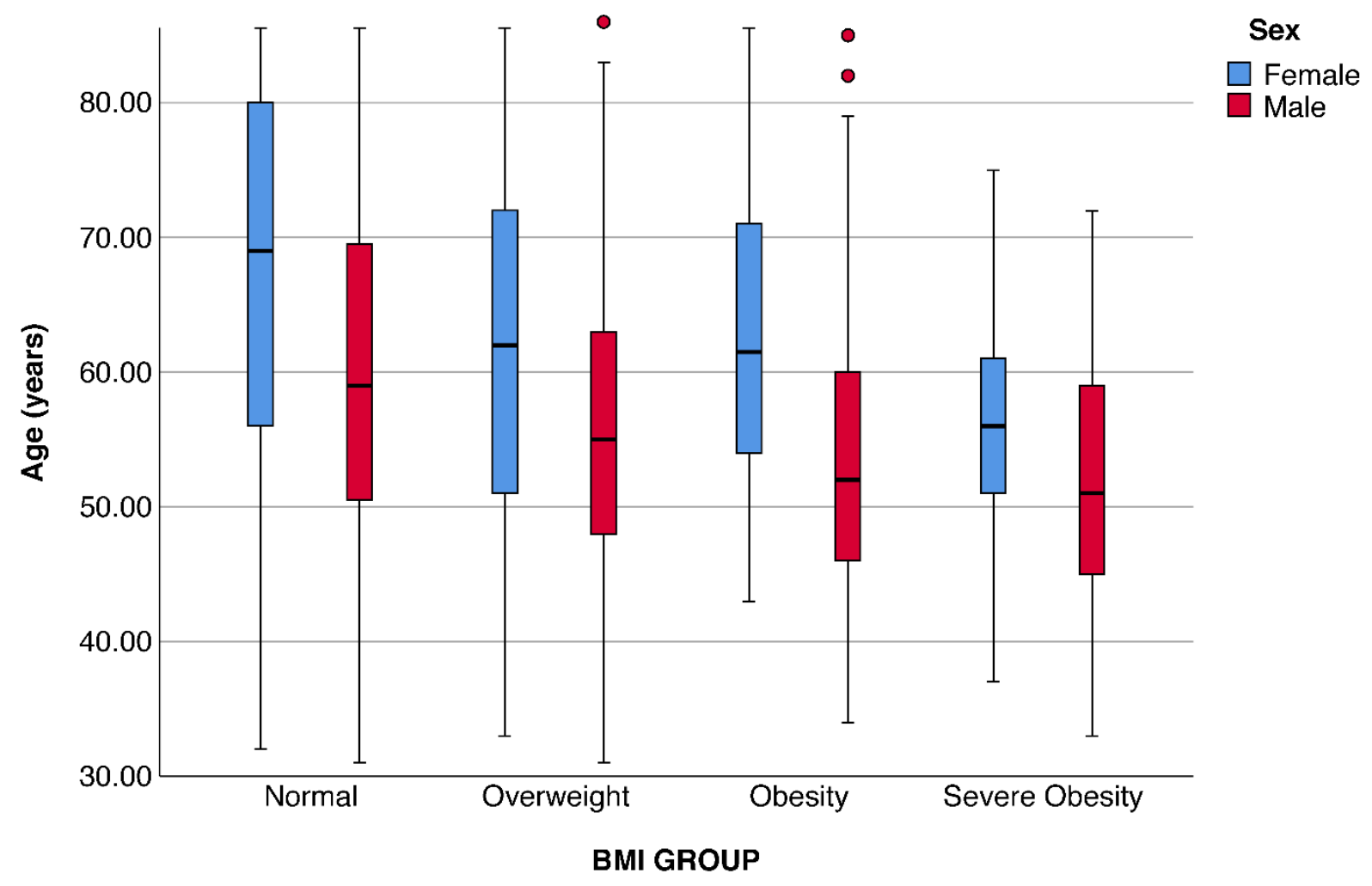

176 Figure 1: Comparison of the mean age of first acute coronary syndrome by body mass

177 index (BMI) groups for both sexes.

When patients were divided into STEMI and NSTEMI/USAP groups, a similar

180 relationship was found between the age at first ACS and the obesity grade. In both groups,

181 the obesity group had a lower age at first ACS than the normal-weight group (Figure 2). The

182 severe-obesity group was likely to have the first episode of NSTEMI and STEMI 11.7 and

1837.1 years earlier than the normal-weight group, respectively $(p<.001)$. 
(a)

All patients

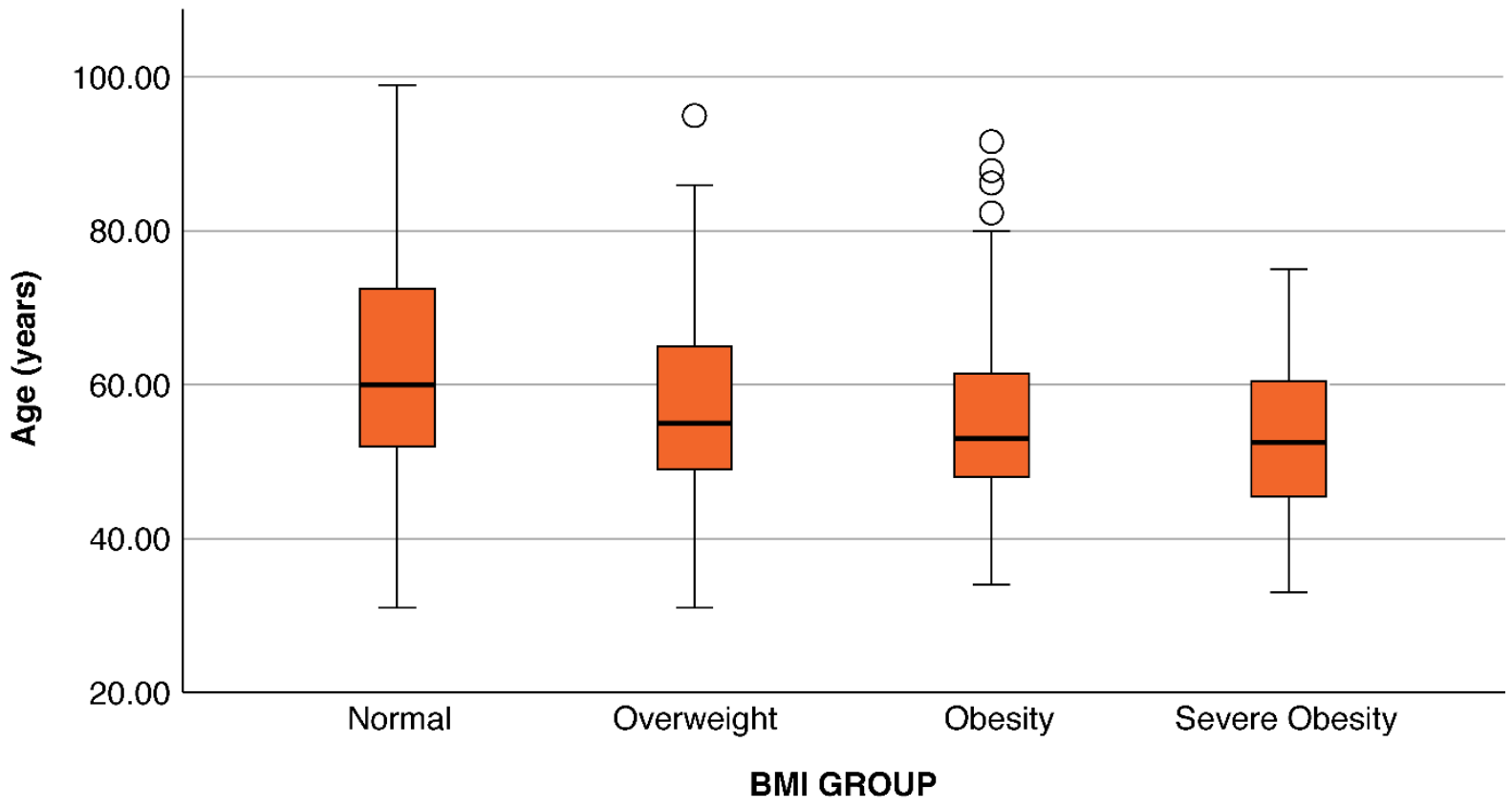

(b) 100.00

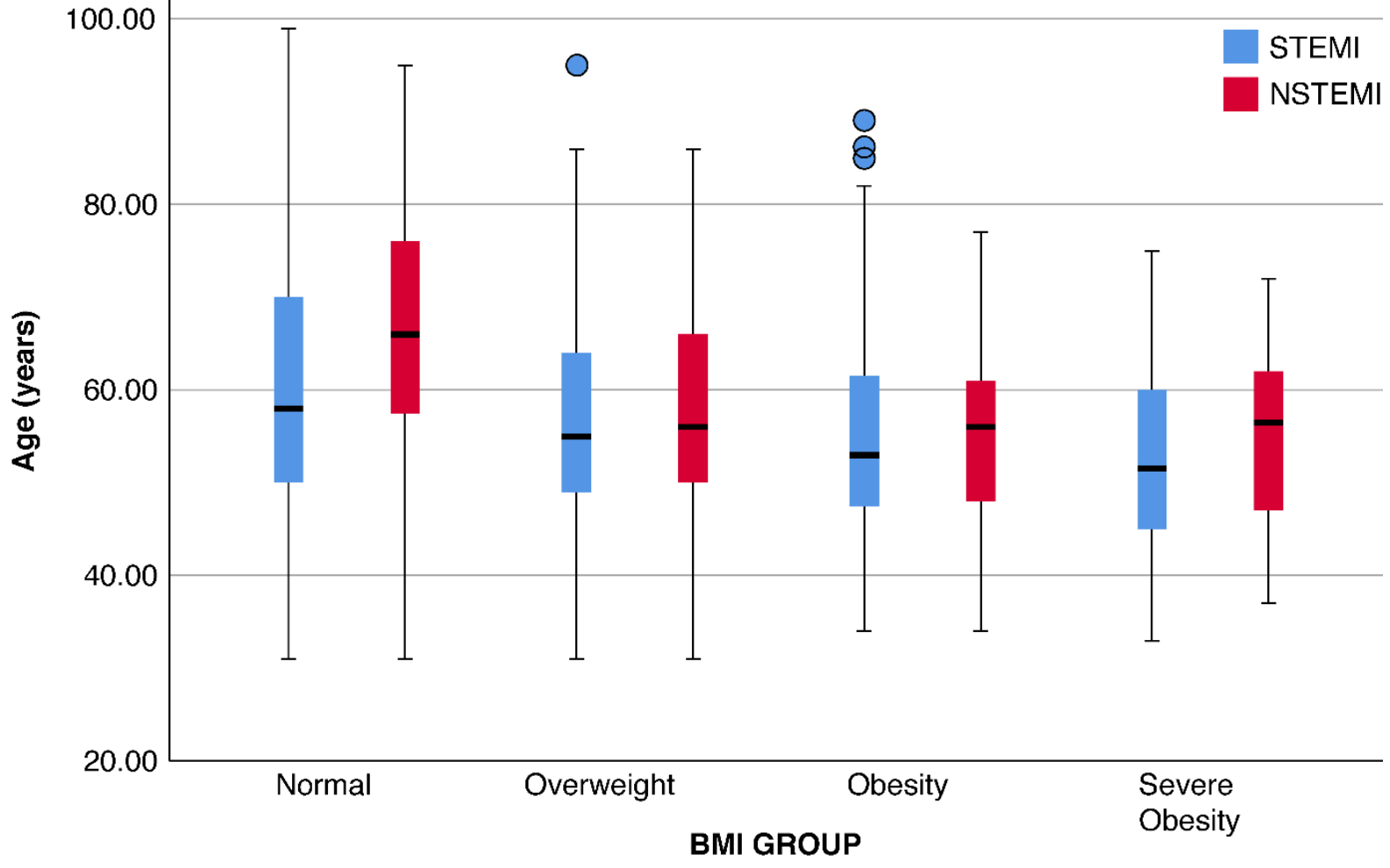

Figure 2: Comparison of the mean age of first acute coronary syndrome by body mass index (BMI) groups (a) for all patients (b) for ST-elevated myocardial infarction

187 (STEMI) and non-ST-elevated myocardial infarction/ unstable angina pectoris

188 (NSTEMI/USAP) patients separately. 

linear regression model. Sex, obesity grade, smoking status, DM, psychosocial stress, and "smoking and sex" and "smoking and DM;" therefore, these interaction terms were added to the model $(p=.001 ;<.001)$. According to the regression model, the differences in the age at first ACS between the normal-weight group and the overweight, grade-I obesity, and severeobesity groups were $-3.4,-5.6$, and -7.1 years, respectively $(p<.001)$; other variables were constant (Figure 3). In addition, the estimated average age during the first ACS episode (with upper and lower limits for 95\% confidence interval) was established for the severe-obesity group (Table 2, Supplementary Table 1). The upper-left corner of the table presents all the risks present in patients, while the lower-right corner is the age calculated for patients with the lowest risk. In the presence of all risk factors, the expected age at first ACS for patients with a LDL-C level of $190 \mathrm{mg} / \mathrm{dl}$ was 48 years. At this risk level, the expected age was the same for both sexes. In patients without risk factors and with a LDL-C value of $70 \mathrm{mg} / \mathrm{dl}$, the mean age at first ACS was 73 for females and 66 for males. In this table, modifiable risk factors include LDL-C, height, smoking, and psychosocial stress. The average age at first ACS of the severe-obesity group without these risk factors was similar to the normal-weight group. A high obesity grade was associated with increased triglyceride values and decreased high-density lipoprotein cholesterol values $(p<0.001)$. In addition, high-density lipoprotein cholesterol values were inversely related to obesity grade $(p<0.001)$. However, the mean 
(a)

All patients

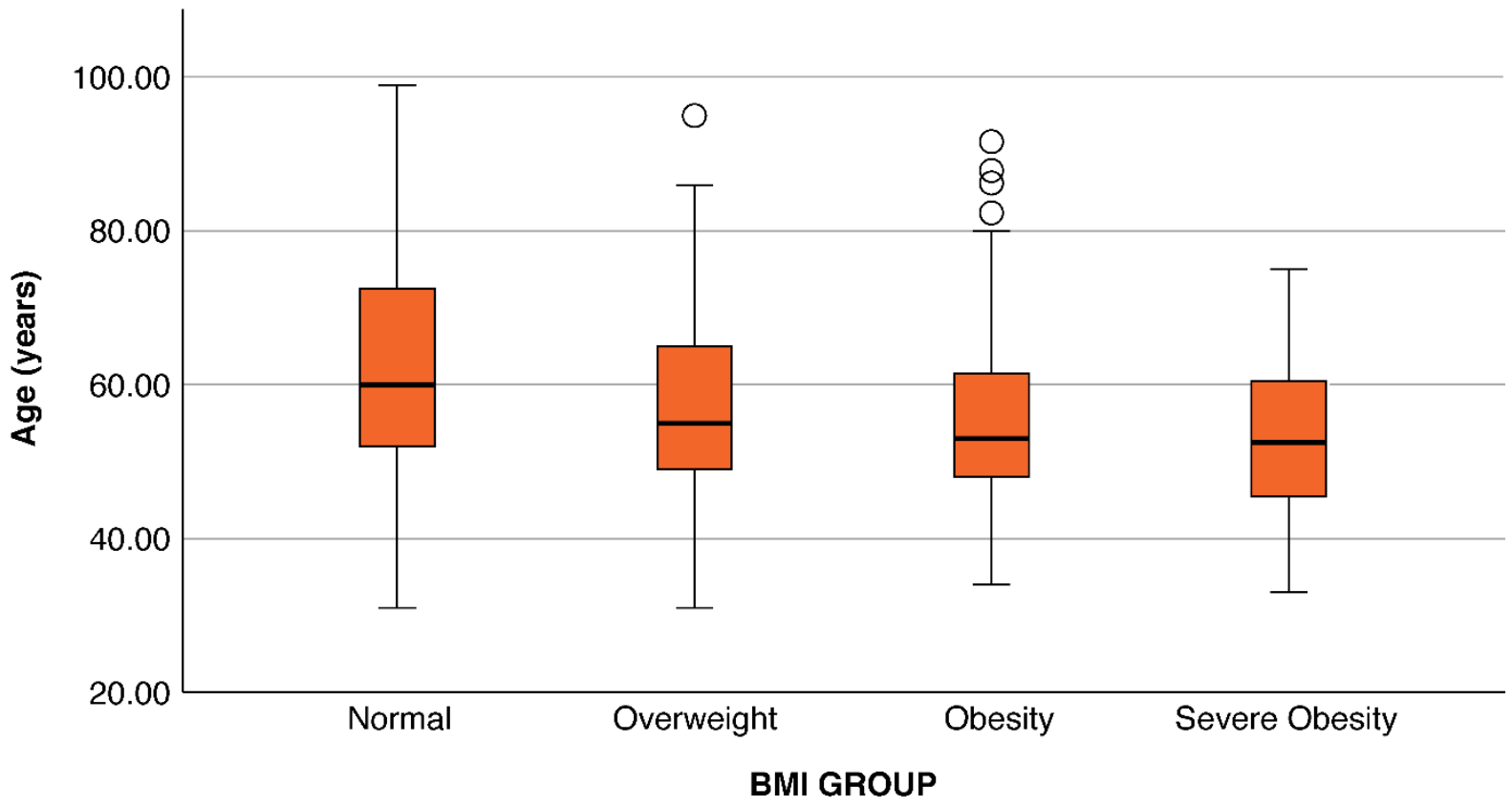

(b)

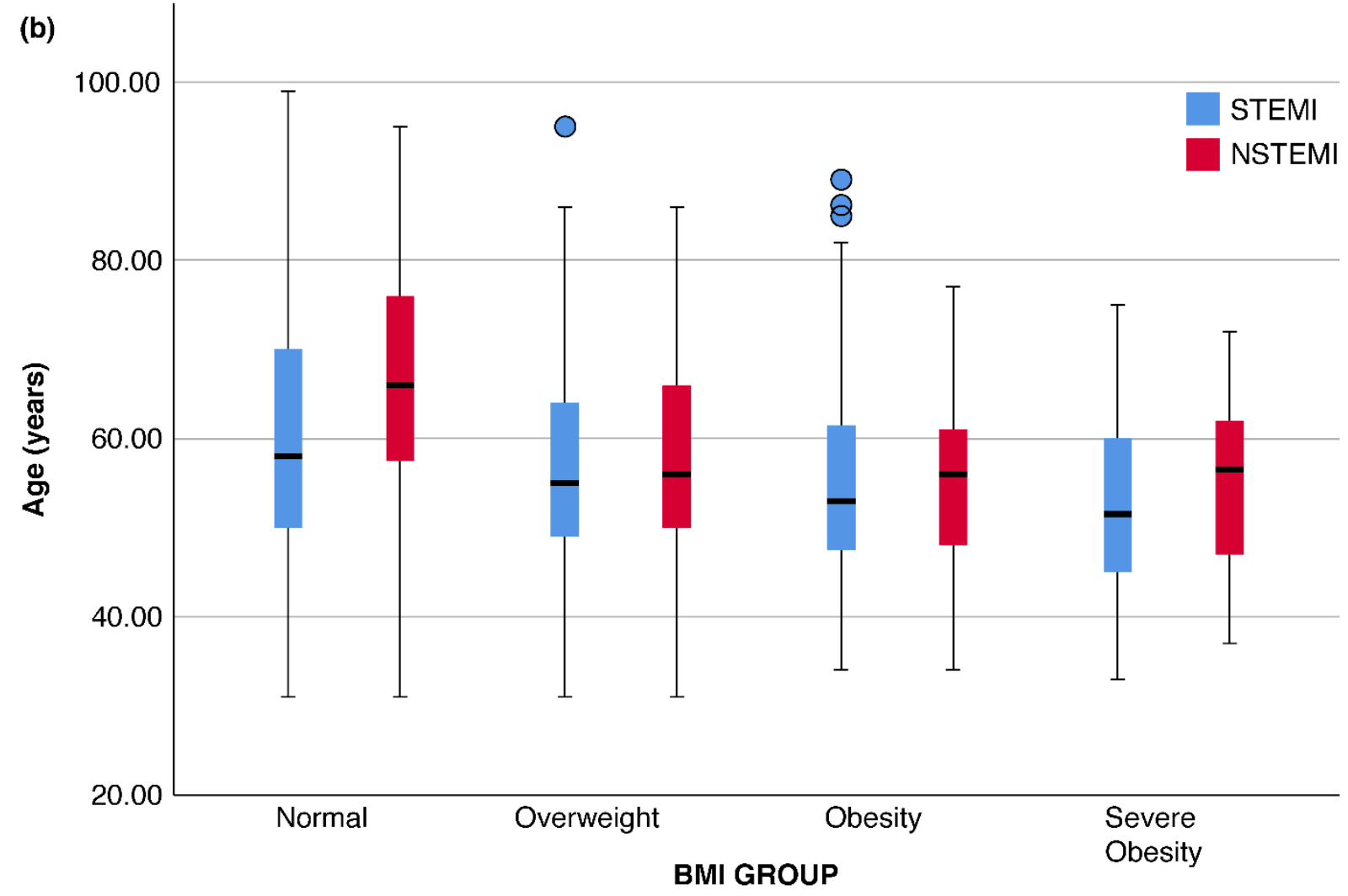

211 Figure 3: Comparison of the mean age of first acute coronary syndrome between the

212 normal weight group and overweight, obesity, and severe-obesity groups. 
Table 2: Effect of risk factors on the age of first acute coronary syndrome

\begin{tabular}{lll}
\hline & $\mathrm{B}$ & $\mathrm{p}$-value \\
\hline Gender & -6.59 & $<0.001$ \\
Smoking & -15.11 & $<0.001$ \\
Diabetes mellitus & -4.63 & 0.001 \\
Psychosocial stress & -5.19 & $<0.001$ \\
Low-density lipoprotein cholesterol & -0.031 & $<0.001$ \\
Overweight-Normal body mass index & -3.54 & $<0.001$ \\
Grade I obesity-Normal body mass index & -5.68 & $<0.001$ \\
Severe obesity-Normal body mass index & -7.34 & $<0.001$ \\
Interaction term: Diabetes mellitus and Smoking & 6.23 & $<0.001$ \\
Interaction term: Gender and Smoking & 6.80 & 0.001
\end{tabular}


Supplementary Table 1: Estimated age at the first episode of acute coronary syndrome (ACS) in patients with severe obesity

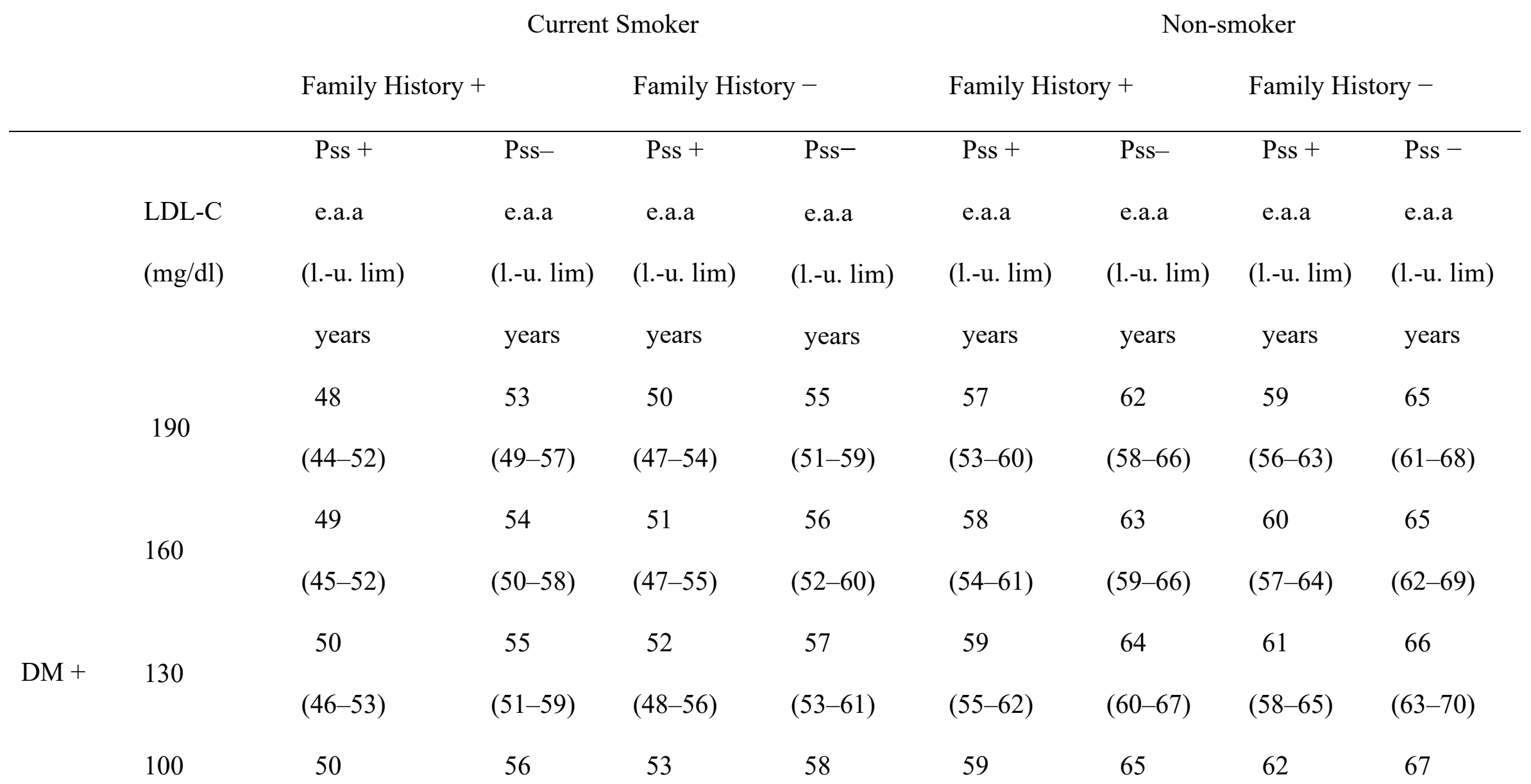




\begin{tabular}{|c|c|c|c|c|c|c|c|c|c|}
\hline \multirow{2}{*}{\multicolumn{2}{|c|}{70}} & $(47-54)$ & $(52-59)$ & $(49-57)$ & $(54-62)$ & $(56-63)$ & $(61-68)$ & $(59-65)$ & $(64-71)$ \\
\hline & & $\begin{array}{l}51 \\
(47-55)\end{array}$ & $\begin{array}{l}56 \\
(52-60)\end{array}$ & $\begin{array}{l}54 \\
(50-58)\end{array}$ & $\begin{array}{l}59 \\
(55-63)\end{array}$ & $\begin{array}{l}60 \\
(57-64)\end{array}$ & $\begin{array}{l}65 \\
(62-69)\end{array}$ & $\begin{array}{c}63 \\
(59-66)\end{array}$ & $\begin{array}{l}68 \\
(64-72)\end{array}$ \\
\hline & 190 & $\begin{array}{l}46 \\
(43-50)\end{array}$ & $\begin{array}{l}51 \\
(48-55)\end{array}$ & $\begin{array}{l}49 \\
(45-52)\end{array}$ & $\begin{array}{l}54 \\
(50-58)\end{array}$ & $\begin{array}{l}61 \\
(58-65)\end{array}$ & $\begin{array}{l}67 \\
(63-70)\end{array}$ & $\begin{array}{l}64 \\
(60-68)\end{array}$ & $\begin{array}{l}69 \\
(65-73)\end{array}$ \\
\hline & 160 & $\begin{array}{l}47 \\
(44-51)\end{array}$ & $\begin{array}{c}52 \\
(49-56)\end{array}$ & $\begin{array}{l}50 \\
(46-53)\end{array}$ & $\begin{array}{l}55 \\
(51-59)\end{array}$ & $\begin{array}{l}62 \\
(59-66)\end{array}$ & $\begin{array}{l}67 \\
(64-71)\end{array}$ & $\begin{array}{c}65 \\
(61-68)\end{array}$ & $\begin{array}{c}70 \\
(66-74)\end{array}$ \\
\hline & 130 & $\begin{array}{l}48 \\
(45-51)\end{array}$ & $\begin{array}{c}53 \\
(50-57)\end{array}$ & $\begin{array}{l}51 \\
(47-54)\end{array}$ & $\begin{array}{c}56 \\
(52-59)\end{array}$ & $\begin{array}{c}63 \\
(60-67)\end{array}$ & $\begin{array}{c}68 \\
(65-72)\end{array}$ & $\begin{array}{c}66 \\
(62-69)\end{array}$ & $\begin{array}{c}71 \\
(67-74)\end{array}$ \\
\hline $\mathrm{DM}-$ & 100 & $\begin{array}{c}49 \\
(45-52)\end{array}$ & $\begin{array}{l}54 \\
(50-58)\end{array}$ & $\begin{array}{l}52 \\
(48-55)\end{array}$ & $\begin{array}{l}57 \\
(53-60)\end{array}$ & $\begin{array}{l}64 \\
(61-67)\end{array}$ & $\begin{array}{c}69 \\
(66-73)\end{array}$ & $\begin{array}{l}67 \\
(63-70)\end{array}$ & $\begin{array}{l}72 \\
(68-75)\end{array}$ \\
\hline & 70 & $\begin{array}{c}50 \\
(46-53)\end{array}$ & $\begin{array}{l}55 \\
(51-59)\end{array}$ & $\begin{array}{l}52 \\
(49-56)\end{array}$ & $\begin{array}{l}58 \\
(54-61)\end{array}$ & $\begin{array}{l}65 \\
(61-68)\end{array}$ & $\begin{array}{l}70 \\
(66-74)\end{array}$ & $\begin{array}{l}67 \\
(64-71)\end{array}$ & $\begin{array}{c}73 \\
(69-76)\end{array}$ \\
\hline
\end{tabular}


Current Smoker

Family History $+\quad$ Family History -
Non-smoker

\begin{tabular}{|c|c|c|c|c|c|c|c|c|c|}
\hline & & \multicolumn{2}{|c|}{ Family History +} & \multicolumn{2}{|c|}{ Family History - } & \multicolumn{2}{|c|}{ Family History +} & \multicolumn{2}{|c|}{ Family History - } \\
\hline & LDL-C & Pss + & Pss- & Pss + & Pss - & Pss + & Pss- & Pss + & Pss - \\
\hline & $(\mathrm{mg} / \mathrm{dl})$ & e.a.a & e.a.a & e.a.a & e.a.a & e.a.a & e.a.a & e.a.a & e.a.a \\
\hline & & (1.-u. $\lim )$ & (1.-u. $\lim )$ & (1.-u. $\lim )$ & (1.-u. $\lim )$ & (1.-u. $\lim )$ & (1.-u. $\lim )$ & (1.-u. $\lim )$ & (1.-u. $\lim )$ \\
\hline & & years & years & years & years & years & years & years & years \\
\hline & 190 & 48 & 53 & 50 & 56 & 50 & 55 & 53 & 58 \\
\hline & & $(45-51)$ & $(50-56)$ & $(47-54)$ & $(52-59)$ & $(46-54)$ & $(51-59)$ & $(49-56)$ & $54-61$ \\
\hline \multirow[t]{7}{*}{$\mathrm{DM}+$} & 160 & 49 & 54 & 51 & 56 & 51 & 56 & 53 & 59 \\
\hline & & $(46-52)$ & $(51-57)$ & $(48-54)$ & $(53-60)$ & $(47-54)$ & $(52-60)$ & $(50-57)$ & $(55-62)$ \\
\hline & 130 & 50 & 55 & 52 & 57 & 52 & 57 & 54 & 59 \\
\hline & & $47-53$ & $(52-58)$ & $(49-55)$ & $(54-60)$ & $(48-55)$ & $(53-60)$ & $(51-58)$ & $(56-63)$ \\
\hline & 100 & 50 & 56 & 53 & 58 & 53 & 58 & 55 & 60 \\
\hline & & $(48-53)$ & $(52-59)$ & $(50-56)$ & $(55-61)$ & $(49-56)$ & $(54-61)$ & $(52-59)$ & $(57-64)$ \\
\hline & 70 & 51 & 56 & 54 & 59 & 54 & 59 & 56 & 61 \\
\hline
\end{tabular}




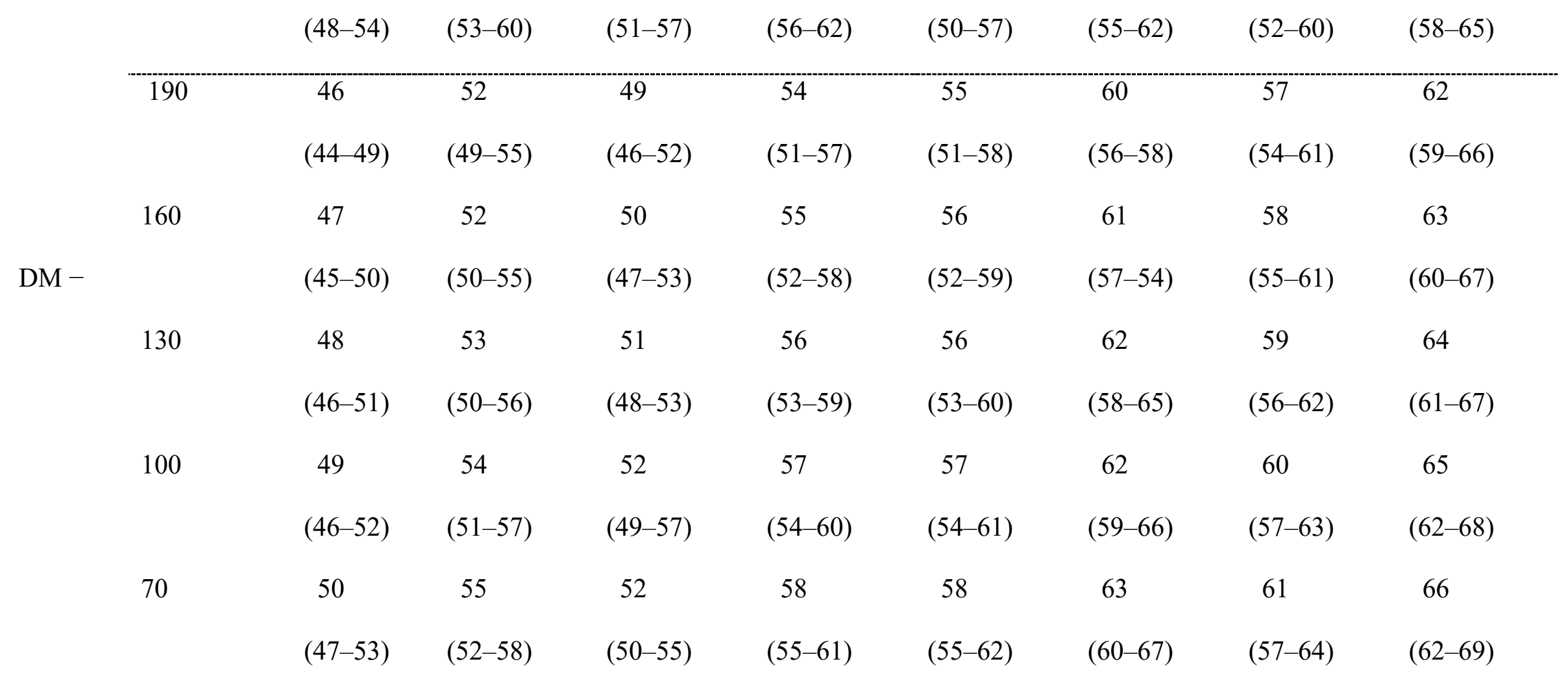

222 DM: Diabetes mellitus, e.a.a: expected average age, LDL-C: Low-density lipoprotein cholesterol, 1.-u. lim: Lower and upper limits for 95\% 223 Confidence interval, Pss: Psychosocial stress. 
This chart shows the age of first ACS calculated for cardiovascular risks in patients with severe obesity. The upper-left corner of the table represents the presence of all risk factors in patients with severe obesity, while the lower-right corner is the case where no risk factors are

227 present. The first estimated ACS age is 48 years for a patient with severe obesity, family history of diabetes mellitus (DM), expressed psychosocial stress, and a LDL-C value of 190 $\mathrm{mg} / \mathrm{dl}$. In females and males with severe obesity and LDL-C values of $70 \mathrm{mg} / \mathrm{dl}$ with no risk factors, the expected age of ACS is 73 and 66 years, respectively. Smoking - sex and smoking - DM interaction terms were included in the regression model; therefore, the estimated age of first ACS was lower in both male and female patients with diabetes who smoked than those who did not smoke. These differences are not statistically significant.

(a)

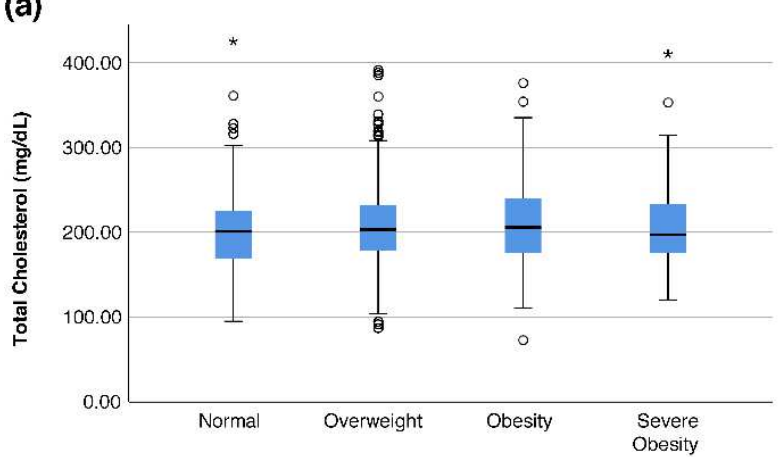

(c)

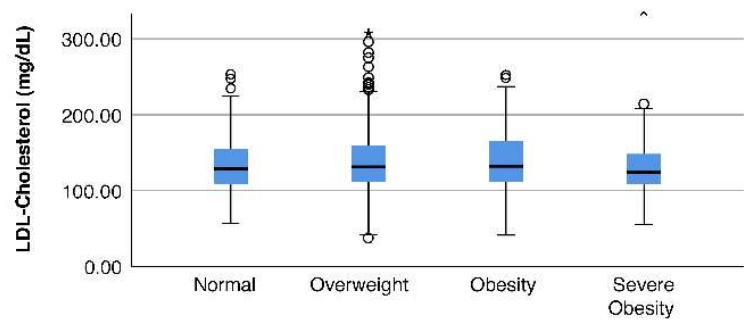

(b)

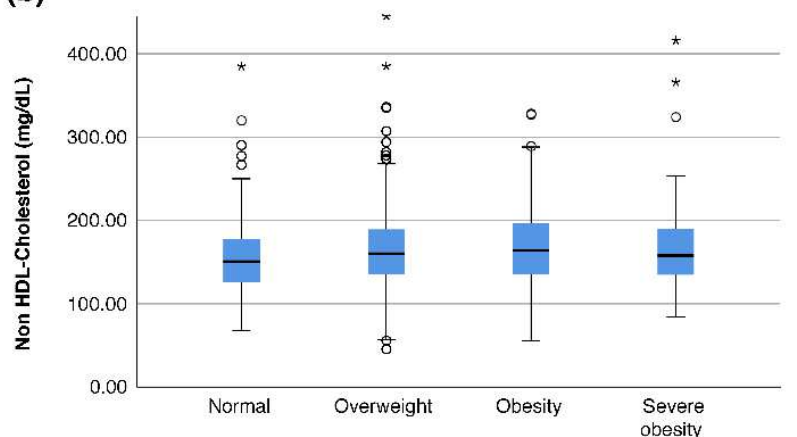

(d)

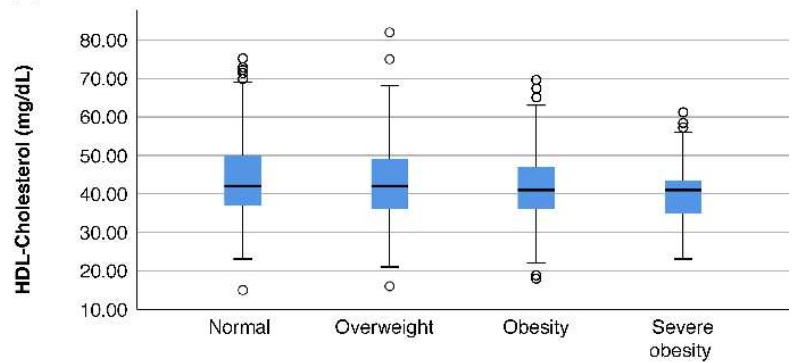


BMI: body mass index, HDL-C: high-density lipoprotein cholesterol, LDL-C: low-density lipoprotein cholesterol, TG: triglyceride, Total-C: total cholesterol

\section{Discussion}

The current study shows that obesity is an independent risk factor for premature ACS. As obesity aggravated, patient's age at first ACS decreased in both sexes. When STEMI and NSTEMI/USAP diagnoses are examined separately, an inverse correlation was found between obesity and the age of first ACS episode. However, females with severe obesity with the least number of risk factors experienced the first ACS episode 27 years later than those with the highest number of risk factors. In males, the age difference was 20 years. Although the body weight remained the same, elimination of modifiable risk factors may significantly delay the age of the first ACS episode. Therefore, controlling the CV risk factors should be as important as controlling the body weight in patients with obesity.

The effect of obesity on the age of patients at first ACS has been seldom studied. Some studies focused on the effect of obesity on STEMI, while others focused on the effect of obesity on the age of patients during NSTEMI; overall, obesity was associated with ACS at an earlier age in both STEMI and NSTEMI groups. However, the effect of obesity on ACS age was different in these studies. Suwaidi et al. showed that patients with obesity are likely to have acute MI onset 8.2 years earlier than those with normal weight after adjustment for sex, smoking status, prodromal angina, Killip class, acute MI history, DM, and HLD [11]. Wienbergen et al. found that patients with obesity experiencing first STEMI were 3 years younger than those with normal weight with first STEMI [14]. In the current study, the corrected age difference between the severe-obesity and normal-weight groups with acute MI was -5.6 years. All these studies emphasize that patients with obesity experience an acute MI 
at an earlier age. Madala et al. showed that patients with severe obesity (BMI $>40 \mathrm{~kg} / \mathrm{m}^{2}$ ) and grade II obesity (BMI 35-40kg/ $\mathrm{m}^{2}$ ) experienced their first MI approximately 12 and 9 years earlier than those with normal weight, respectively [10]. The current study showed that grade II and grade III obesity were classified as severe obesity and that the age difference between the severe-obesity $\left(\mathrm{BMI}>35 \mathrm{~kg} / \mathrm{m}^{2}\right)$ and normal-weight $\left(\mathrm{BMI}<25 \mathrm{~kg} / \mathrm{m}^{2}\right)$ groups with NSTEMI/USAP was -10.1 years. Additionally, the average age of patients with normal weight experiencing ACS is younger than the average age determined in other studies.

However, the ACS age of the normal-weight group in our study is close to that of the severeobesity group in other similar studies $[10,11,14]$. This finding may be related to the idea that these studies were conducted in different societies. Although our data inadequately represent the Turkish community, our study revealed that the age at first ACS episode in our country is lower and that the mean age of ACS varies between countries. In the recently published multicenter TURKMI study, the MI age range is, in fact, close to the MI age range in our study [15]. Similar to our study, the TURKMI study demonstrated that patients with MI in Turkey were younger than those in developed countries. psychosocial stress, and LDL-C levels were independent variables that affect the age of first ACS episode. Sex, DM, HLD, HTN, family history, and smoking are the traditional risk factors for coronary artery disease. Modification of DM, HLD, HTN, and smoking risk factors is crucial for preventing CV events [16]. Smoking, family history of premature CHD, and male sex among young patients with MI were more prevalent than those among their older counterparts [17].

According to our analysis, HTN was not related to premature ACS, probably because of the prevalence of HTN that changes with age. HTN was prevalent by $19 \%$ in patients aged $<45$ years and by $58 \%$ in patients aged $>75$ years in our study population. Similarly, in Gulf 
RACE and Gulf RACE-2, HTN is less prevalent in younger individuals with ACS than in older individuals with ACS. Furthermore, GISSI-2 showed that the risk of MI (0.45 [0.40$0.50])$ is lower in younger ( $<50$ years) than in older (50-70 years) individuals with HTN [18].

In the last few decades, the incidence of obesity and DM has increased at younger ages. This situation could lead them to premature ACS [2]. In addition to these traditional risk factors, nontraditional risk factors (e.g., human immunodeficiency virus, inflammatory diseases, recreational drug use, and psychosocial stress) are associated with premature atherosclerotic events [19]. Chronic stress is associated with a considerable risk for CHD incidence, supporting the notion that stress is a causal CHD risk factor. Furthermore, studies involving survivors of ACS suggested that acute emotional stress can trigger ACS [20, 21].

The findings support the hypothesis that obesity is independently linked with the premature occurrence of ACS. Adipose tissue is not only involved in energy storage but also acts as an endocrine organ that secretes various bioactive substances. Irregular expression of these factors caused by excessive fat and adipocyte dysfunction is associated with the pathogenesis of various disease processes through altered immune responses [22-24]. Obesity is a chronic, low-grade inflammatory condition that contributes to the development of obesity-related disorders, particularly because of metabolic dysfunction [25, 26].

Additionally, patients with a high BMI are associated with impaired microvascular coronary endothelial dependent function [27]. Considering these physiopathological mechanisms, obesity results in wide-ranging diseases that reduce life expectancy, such as insulin resistance, type $2 \mathrm{DM}$, atherosclerosis, and ischemic heart disease, further leading to great economic and social consequences [28, 29]. Previous meta-analysis showed that if the normal-weight limit exceeds, the mortality rate increases linearly with BMI [30]. In the upper BMI range $\left(25-50 \mathrm{~kg} / \mathrm{m}^{2}\right)$, each $5 \mathrm{~kg} / \mathrm{m}^{2}$ higher BMI is associated with approximately $40 \%$ higher mortality in ischemic heart disease. Ischemic CAD is associated with lower life 
expectancy $[1,31,32]$. Therefore, initiating CV preventive treatment in patients with obesity at an earlier age is important. However, the risk algorithms used by current guidelines do not consider obesity or BMI increase as an independent risk factor [33]. In preventive treatment recommendations, considering the relationship between obesity and ACS at an earlier age may be beneficial.

Some people with obesity are protected from many of the adverse metabolic effects of excess body fat tissue, indicating a "metabolically healthy" state. Unfortunately, MHO has no any universally accepted description. Most investigators define $\mathrm{MHO}$ as having either 0,1 , or 2 metabolic syndrome components [34]. The risk of CV events does not increase significantly in people identified as $\mathrm{MHO}[35,36]$. The main risk increase is in MUO. The risk of $\mathrm{CV}$ events in MONW individuals is higher than in MHO. The current study was not designed to examine $\mathrm{MHO}, \mathrm{MUO}$, and MONW groups separately; however, the effect of $\mathrm{CV}$ risk factors was investigated. The presence of $\mathrm{CV}$ risk factors in people with severe obesity makes the age of ACS noticeably younger, consistent with the findings of increased CV risk in individuals with MUO. Additionally, in line with the MHO concept, CV events can be delayed in patients without risk factors. However, the kind of approach that should be used in patients with obesity remains unclear. Is weight loss an absolute goal in patients with obesity? According to a recent article regarding patients with pre-DM or type $2 \mathrm{DM}$ presenting with obesity, weight loss was related to higher all-cause and CV mortality compared with the lack of weight loss; such relationship was not observed in weight gain [37]. In preventing or delaying CV events, the same approach given to all people with obesity may be incorrect and the main goal should not be to lose weight. A recent study showed that weight loss was an independent risk factor for higher mortality than no weight loss in prediabetes or type $2 \mathrm{DM}$ patient with obesity [37]. Detecting whether CV risk factors are present and eliminating the modifiable ones may benefit patients with severe obesity. 

center design; however, the characteristics of the patient group are compatible with the multicenter TURKMI study [15]. The study was conducted in the center with the highest ACS patient burden in Antalya. Antalya is one of the cities in Turkey with the highest number of immigrants. When the data were analyzed according to the immigration status of the patients, it was observed that half of the participating patients were migrants from other provinces, and 501 patients had emigrated from Turkey's 12 different geographical regions (Supplementary Table 2). Although our study was not planned as a multicenter study, patients from all geographical regions were included in the study.

Supplementary Table 2: Distribution of migrated patients by regions of Turkey

\begin{tabular}{lll}
\hline & $\mathrm{n}$ & $\%$ \\
\hline Istanbul Region (TR1) & 16 & 3.2 \\
West Marmara Region (TR2) & 25 & 5.0 \\
East Marmara Region (TR4) & 9 & 1.8 \\
Aegean Region (TR3) ( & 67 & 134 \\
West Anatolia Region (TR5) & 51 & 10.2 \\
Mediterranean Region (TR6) & 102 & 20.4 \\
Central Anatolia Region (TR7) & 48 & 9.6 \\
West Black Sea Region (TR8) & 41 & 8.2 \\
East Black Sea Region (TR9) & 26 & 5.2 \\
Northeast Anatolia Region (TRA) & 28 & 5.6 \\
Central East Anatolia Region (TRB) & 35 & 7.0 \\
Southeast Anatolia Region (TRC) & 53 & 10.6 \\
Total immigration patients & 501 & 100.0 \\
\hline
\end{tabular}


Furthermore, the number of patients in the severe-obesity group is relatively low; more studies involving this group of patients are needed. In addition, results should be tested with prospective cohort studies in patients with obesity. Nonetheless, the current study provides data for risk factors to be studied in prospective cohort studies.

Another limitation of our study is that we did not use specific questionnaires to define psychosocial stress; thus, we could not make a more detailed psychological evaluation. Furthermore, ACS may have possibly affected patients' answers. The tests to be used in stress assessments would affect the current ACS and coronary intensive care admission period. For this reason, instead of providing questions that would emphasize on the patient's current feelings, we provided questions that would emphasize on whether the patients had a stressful character or life. To mitigate this disadvantage, we asked such questions when patient's condition was stable. We also emphasized to give an answer considering the situation before the event. Despite all these interventions, the reliability of psychosocial stress factor assessment during ACS is still controversial. Findings need to be evaluated in prospective cohort studies. However, excluding psychosocial stress status in the analysis may also create a scientific deficiency.

In addition, the fact that the study covers a period of 5 years may cause limitations in terms of standardization of laboratory results. In the laboratory reviews included in the study within this time period, the kit or calculation methods remained the same.

An important difference between our study and other similar studies was that we included patients with culprit lesions in CAG, and excluded those without CAG. Moreover, patients diagnosed with Type $1 \mathrm{MI}$ were included in the study, and other types of AMI were excluded. Thus, a more specific patient group was formed to calculate the age of the first ACS due to atherosclerotic plaque rupture. In addition, patients using drugs, such as statin 
372 and antiplatelet that affect the first ACS age, were excluded from the study. Hence, confusing

373 factors were removed before calculating the first ACS age.

\section{Conclusions}

Patients with severe obesity experienced their first ACS episode 7 years earlier than

376 those with normal weight. However, the absence of CV risk factors in people with obesity

377 eliminated the potential negative effect of obesity on the ACS age. For the prevention of

378 premature ACS in individuals with obesity, the necessity of additional prevention strategy at

379 an early age should be investigated through prospective cohort studies.

\section{$380 \quad$ List of abbreviations}

381 ACE-I: angiotensin converting enzyme-inhibitors

382 ACS: acute coronary syndrome

383 ARB: angiotensin receptor blockers

384 BB: beta blockers

385 BMI: body mass index

386 CV: cardiovascular

387 CVD: cardiovascular disease

388 HLD: hyperlipidemia

389 HTN: hypertension

390 LDL-C: low-density lipoprotein cholesterol

391 MHO: metabolically healthy obese

392

MI: myocardial infarction 
MONW: metabolically obese but has a normal weight

MUO: metabolically unhealthy obese

NSTEMI: non-ST-elevated myocardial infarction

STEMI: ST-elevated myocardial infarction

397

USAP: unstable angina pectoris

Ethics approval and consent to participate: This was approved by the ethics committee of Antalya Training and Research Hospital, University of Health Sciences (2014-097). Written informed consent was obtained from all participants.

401

Consent for publication:

402

Availability of data and materials: The datasets generated during and/or analyzed during the current study are available from the corresponding author on reasonable request.

404

405

Competing interests: The authors have no conflicts of interest to declare.

406

407

Funding: Not applicable

Authors' contributions:

(1) Study conception and design: DD. (2) Data processing and preliminary analyses:

DD. (3) Literature searches and reviewing: DD, DED. (4) Data analysis: DD. (5)

Manuscript writing: DD, DED. (6) Editing and reviewing: all authors. All authors read and approved the final manuscript 
Acknowledgments: We would like to thank Prof. Dr. Atila Halil Elhan for statistical analysis support and Enago (www.enago.com) for English language review.

Authors' information:

\section{Affiliations}

Cardiology department, Antalya training and research hospital; Deniz Demirci, Duygu

\section{Ersan Demirci}

\section{References}

424 [1] Adair T, Lopez AD. The role of overweight and obesity in adverse cardiovascular disease mortality trends: an analysis of multiple cause of death data from Australia and the USA. BMC Med. 2020;18:199.

[2] Vikulova DN, Grubisic M, Zhao Y, Lynch K, Humphries KH, Pimstone SN, Brunham

LR. Premature atherosclerotic cardiovascular disease: trends in incidence, risk factors, and sex-related differences, 2000-2016. J Am Heart Assoc. 2019;8:e012178.

[3] Xi B, Liang Y, Liu Y, et al. Tobacco use and second-hand smoke exposure in young adolescents aged 12-15 years: data from 68 low-income and middle-income countries. Lancet Glob Health. 2016;4:e795-e805.

[4] Despres JP, Larose E, Poirer P. Obesity and cardiometabolic disease. In: Douglas P, PL

Disease: A Textbook of Cardiovascular Medicine. USA: Elsevier; 2019. 998-1006. 
[5] NCD Risk Factor Collaboration (NCD-RisC). Trends in adult body-mass index in 200

437

438

439

440

441

442

443

444

445

446

447

448

449

450

451

452

453

454

455

456

457

458

countries from 1975 to 2014: a pooled analysis of 1698 population-based measurement studies with 19·2 million participants. Lancet. 2016;387:1377-96.

[6] Lavie CJ, Laddu D, Arena R, et al. Healthy weight and obesity prevention: JACC Health Promotion series. J Am Coll Cardiol. 2018;72:1506-31.

[7] Kitahara CM, Flint AJ, Berrington de Gonzalez A, et al. Association between class III obesity (BMI of 40-59 kg/m2) and mortality: a pooled analysis of 20 prospective studies. PLOS Med. 2014;11:e1001673.

[8] Iacobini C, Pugliese G, Blasetti Fantauzzi C, et al. Metabolically healthy versus metabolically unhealthy obesity. Metabolism. 2019;92:51-60.

[9] Kouvari M, Panagiotakos DB, Chrysohoou C, et al. A sex-specific evaluation of predicted lean and fat mass composition and cardiovascular disease onset and progression: A combined analysis of the Attica and GREECS prospective epidemiological studies. Obes Res Clin Pract. 2019;13:469-77.

[10] Madala MC, Franklin BA, Chen AY, et al. Obesity and age of first non-ST-segment elevation myocardial infarction. J Am Coll Cardiol. 2008;52:979-85.

[11] Suwaidi JA, Wright RS, Grill JP, et al. Obesity is associated with premature occurrence of acute myocardial infarction. Clin Cardiol. 2001;24:542-7.

[12] Thygesen K, Alpert JS, Jaffe AS, et al. Fourth universal definition of myocardial infarction (2018). Circulation. 2018;138:e618-51.

[13] Friedewald WT, Levy RI, Fredrickson DS. Estimation of the concentration of lowdensity lipoprotein cholesterol in plasma, without use of the preparative ultracentrifuge. Clin Chem. 1972;18:499-502. 
[14] Wienbergen H, Gitt AK, Juenger C, et al. Impact of the body mass index on occurrence and outcome of acute ST-elevation myocardial infarction. Clin Res Cardiol. 2008;97:83-8.

461

462

[15] Erol MK, Kayıkçığlu M, Kılıçkap M, et al. Baseline clinical characteristics and patient profile of the TURKMI registry: results of a nation-wide acute myocardial infarction registry in Turkey. Anatol J Cardiol. 2020;24:43-53.

[16] Collet JP, Thiele H, Barbato E, et al. ESC Guidelines for the management of acute coronary syndromes in patients presenting without persistent ST-segment elevation, supplementary data. Eur Heart J. 2020;2020:22-5.

[17] Shah N, Kelly AM, Cox N, et al. Myocardial infarction in the "young": risk factors, Presentation, Management and Prognosis, Presentation. Heart Lung Circ. 2016;25:955-60.

[18] Dugani SB, Murad W, Damilig K, et al. Premature myocardial infarction in the Middle East and North Africa: rationale for the Gulf PREVENT Study. Angiology. 2020;71:17-26.

[19] Mahtta D, Khalid U, Misra A, et al. Premature atherosclerotic cardiovascular disease: what have we learned recently? Curr Atheroscler Rep. 2020;22:44.

[20] Turner AI, Smyth N, Hall SJ, et al. Psychological stress reactivity and future health and disease outcomes: A systematic review of prospective evidence. Psychoneuroendocrinology. 2020;114:104599.

[21] Wirtz PH, von Känel R. Psychological stress, inflammation, and coronary heart disease. Curr Cardiol Rep. 2017;19:111.

[22] Chait A, den Hartigh LJ. Adipose tissue distribution, inflammation and its metabolic consequences, including diabetes and cardiovascular disease. Front Cardiovasc Med. 2020;7:22. 
[23] Rafeh R, Viveiros A, Oudit GY, et al. Targeting perivascular and epicardial adipose

482

483

484

485

486

487

tissue inflammation: therapeutic opportunities for cardiovascular disease. Clin Sci.

$2020 ; 134: 827-51$

[24] Al-Talabany S, Mordi I, Graeme Houston J, et al. Epicardial adipose tissue is related to arterial stiffness and inflammation in patients with cardiovascular disease and type 2 diabetes. BMC Cardiovasc Disord. 2018;18:31.

[25] Cooke AA, Connaughton RM, Lyons CL, et al. Fatty acids and chronic low grade inflammation associated with obesity and the metabolic syndrome. Eur J Pharmacol. 2016;785:207-14.

[26] Cruz KJC, de Oliveira ARS, Morais JBS, et al. Role of microRNAs on adipogenesis, chronic low-grade inflammation, and insulin resistance in obesity. Nutrition. 2017;35:28-35

[27] Worthley MI, Curtis MJ, Goodhart DM, et al. Obesity is associated with impaired human coronary endothelial function. Obes Res Clin Pract. 2009;3:1-52.

[28] Blouin C, Hamel D, Vandal N, et al. The economic consequences of obesity and overweight among adults in Quebec. Can J Public Health. 2017;107:e507-13.

[29] Chu DT, Minh Nguyet NT, Dinh TC, et al. An update on physical health and economic consequences of overweight and obesity. Diabetes Metab Syndr. 2018;12:1095-100.

[30] Global BMI Mortality Collaboration B, Di Angelantonio E, Bhupathiraju ShN, et al. Body-mass index and all-cause mortality: individual-participant-data meta-analysis of 239 prospective studies in four continents. Lancet. 2016;388:776-86.

[31] Ellis CJ, Gamble GD, Williams MJA, et al. All-cause mortality following an acute coronary syndrome: 12-year follow-up of the comprehensive 2002 new zealand acute coronary syndrome audit. Heart Lung Circ. 2019;28:245-56. 
504 [32] Pocock SJ, Huo Y, Van de Werf F, et al. Predicting two-year mortality from discharge

505 after acute coronary syndrome: an internationally based risk score. Eur Heart J Acute

506 Cardiovasc Care. 2019;8:727-37.

507 [33] Mach F, Baigent C, Catapano AL, et al. 2019 ESC/EAS Guidelines for the management

508 of dyslipidaemias: lipid modification to reduce cardiovascular risk. Eur Heart J. 2020;41:11150988.

510 [34] Smith GI, Mittendorfer B, Klein S. Metabolically healthy obesity: facts and fantasies. J

511 Clin Invest. 2019;129:3978-89.

512 [35] Gaiţă D, Moşteoru S. Metabolically healthy versus unhealthy obesity and risk for

513 diabetes mellitus and cardiovascular diseases. Cardiovasc Endocrinol. 2017;6:23-6.

514 [36] Karelis AD. Metabolically healthy but obese individuals. Lancet. 2008;372:1281-3.

515 [37] Doehner W, Gerstein HC, Ried J, et al. Obesity and weight loss are inversely related to

516 mortality and cardiovascular outcome in prediabetes and type 2 diabetes: data from the

517 ORIGIN trial. Eur Heart J. 2020;41:2668-77. 
Figures

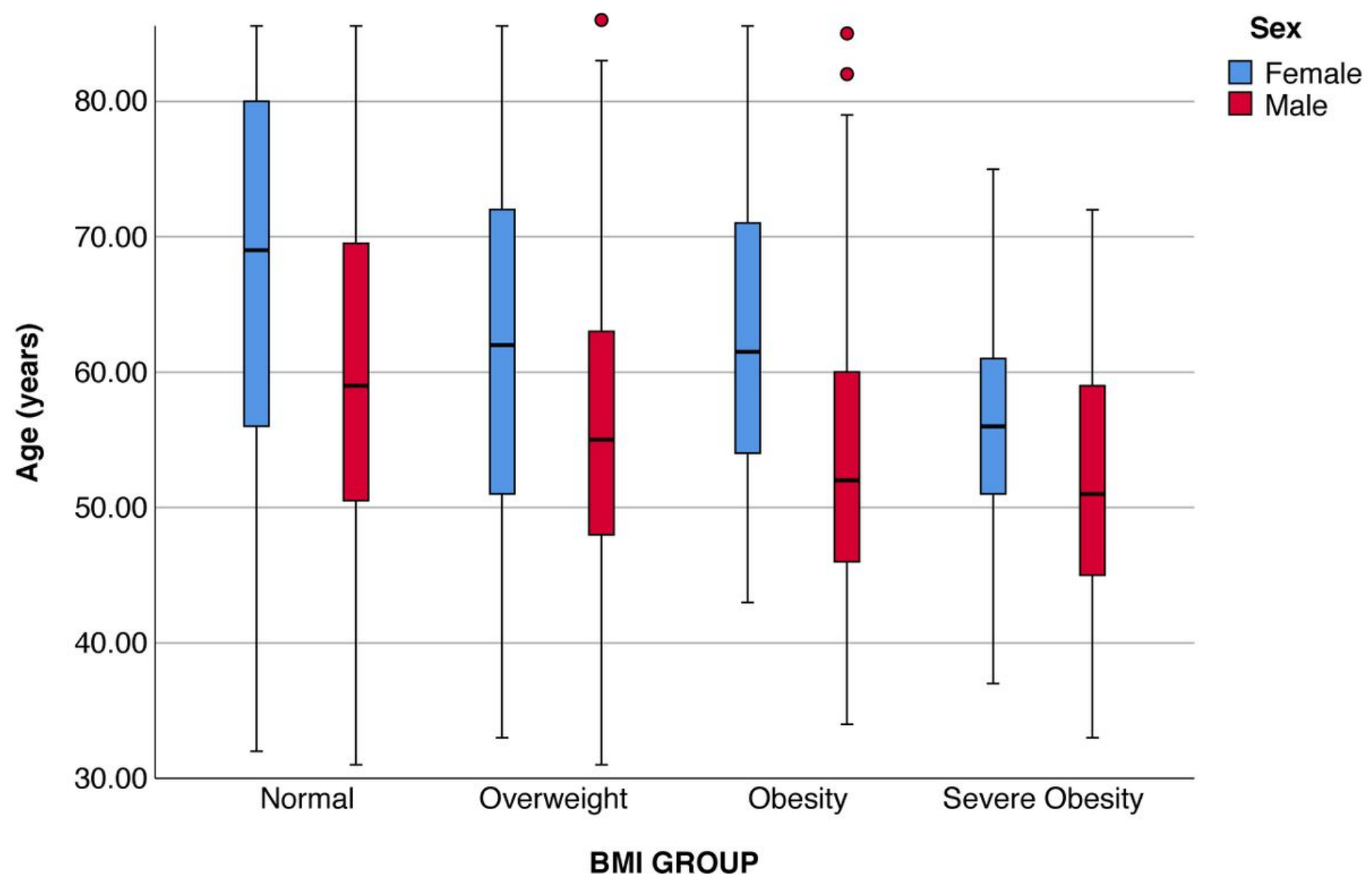

Figure 1

Comparison of the mean age of first acute coronary syndrome by body mass index groups for both sexes. BMl: body mass index 
(a)
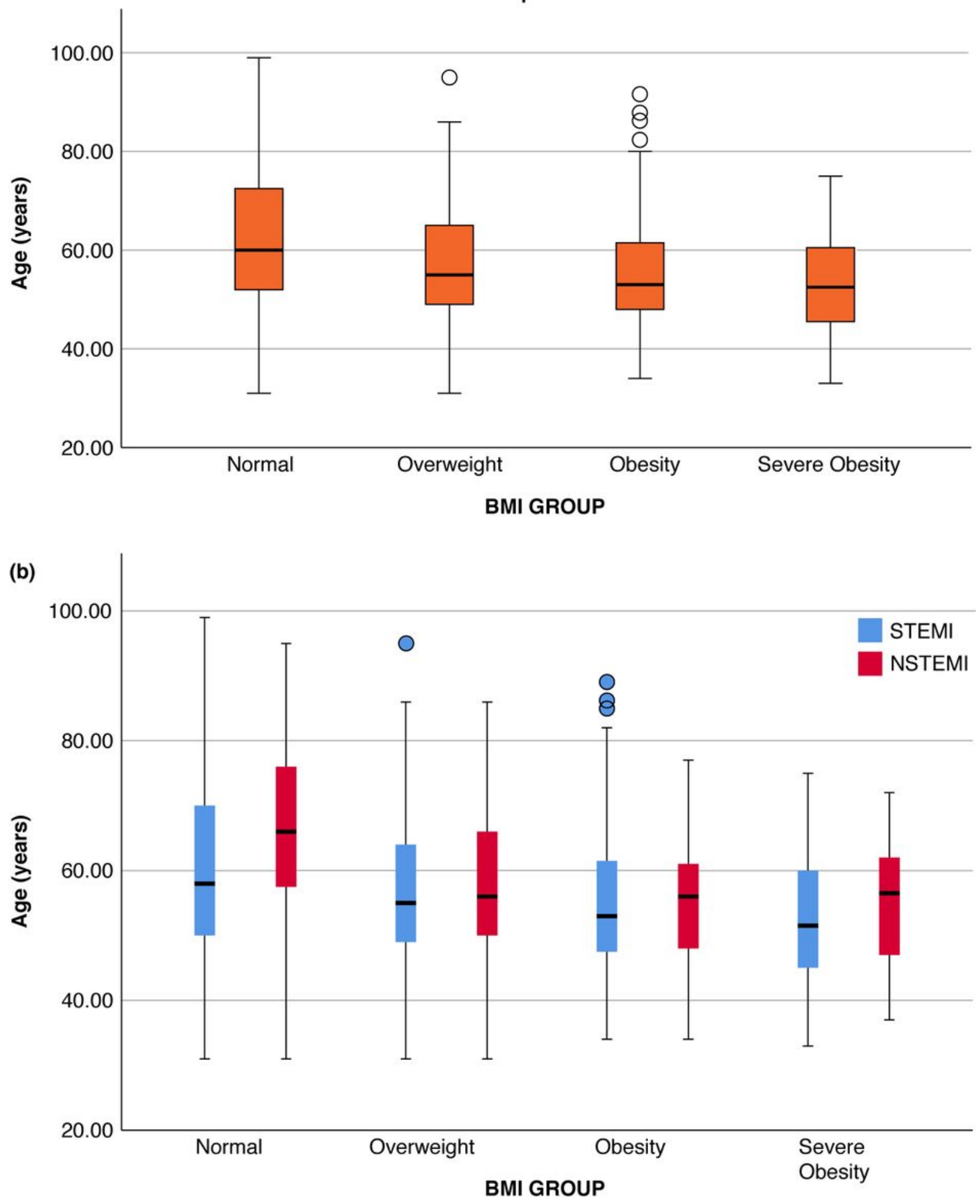

Figure 2

Comparison of the mean age of first acute coronary syndrome by body mass index groups $A$ ) for all patients B) for STEMI and NSTEMI/USAP patients separately BMI: body mass index, NSTEMI: non-STelevated myocardial infarction, STEMI: ST-elevated myocardial infarction. USAP: unstable angina pectoris 
(a)
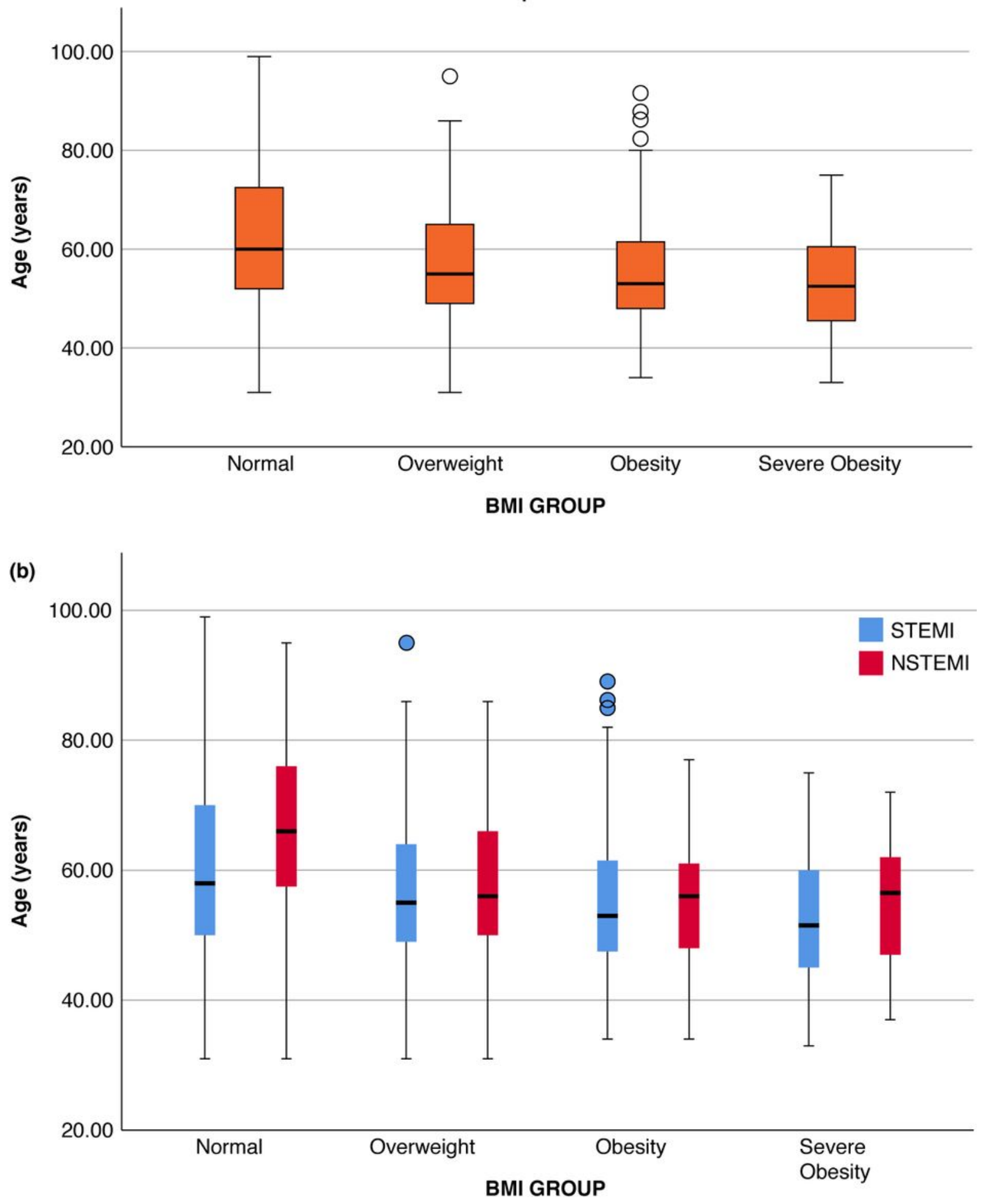

Figure 3

Comparison of the mean age of first acute coronary syndrome between the normal weight group and overweight, obesity, and severe-obesity groups BMI: body mass index, NSTEMI: non-ST elevation myocardial infarction, STEMI: ST elevation myocardial infarction. USAP: unstable angina pectoris

\section{Supplementary Files}


This is a list of supplementary files associated with this preprint. Click to download.

- Supplementarydata.docx 